\title{
EEN CHINEES GOUDEN HERT OPNIEUW IN DE BELANGSTELLING
}

Een elegant hert staat met gestrekte benen rank op de hoge hoeven (afb. 1). Het dier is enigszins gestileerd weergeven, met het hoofd en vooral de nek in een langerekte vorm. Deze sierlijke houding maakt dat het beeld zich ieder moment van het lapis lazuli voetstuk lijkt te kunnen gaan verheffen, iets dat nog eens wordt benadrukt door het golvende staartje. De pose maakt gelijk duidelijk dat het hier niet om een alledaags exemplaar gaat maar om een bovennatuurlijk hert, iets dat nog eens te meer blijkt uit het feit dat het beest een lingzhi, de 'zwam der onsterfelijkheid', in de mond houdt. Het geheel is mogelijk in Europa - gezet op een rechthoekig blokje lapis lazuli.

Zoals vaak het geval is met Chinese symboliek is de uitspraak van het karakterteken, in het geval van hert $l u$, homofoon aan een ander karakter met een gunstige betekenis. In dit geval is dat het karakter voor 'goed inkomen'. Het hert is zo een symbool voor ambtelijke voorspoed en het welvarende leven dat met een hoge functie gepaard gaat. De lingzhi in de mond maakt de wens kenbaar dat dit tot op hoge leeftijd genoten mag worden.

\section{Het hert, de paddestoel en de God van het Lange Leven}

De combinatie van hert en magische paddestoel wordt wel verklaard met de bewering dat het hert het enige wezen zou zijn dat de paddestoel zou kunnen vinden. In handboeken en catalogi is deze uitleg keer op keer terug te vinden, al blijft de oorsprong van de legende onvermeld. ${ }^{1}$ Jan Fontein, conservator van de collectie van de Vereniging van 1955 tot 1966, vatte de symboliek rond het hert en de lingzhi ook al eens samen in een artikel over dit beeldje. ${ }^{2}$ Hij wees op de mogelijkheid dat dergelijke legenden juist ontstonden om een al bestaande iconografische combinatie te verklaren, in plaats dat het de kunstvorm was die uitdrukking gaf aan een oude vertelling.

De connotatie van onsterfelijkheid bij paddestoelen was al vroeg in het Chinese denken aanwezig. De 3e-eeuwse tekst 'Op zoek naar het bovennatuurlijke' (Soushenji) vermeldt de persoon Pengzu uit het tweede millennium v.Chr., die naar verluidde een leeftijd van 700 jaar had bereikt op een dieet van lingzhi. ${ }^{3}$ Ook de taoïstische kluizenaars 'de vier wijzen van de Berg Shang' overleefden in hun teruggetrokken bestaan op de berg met slechts paddestoelen als voedsel. ${ }^{4}$

Het hert werd evenzo al in de oudheid magische krachten toegedicht, op verschillende plaatsen op het Chinese continent. Zo werden op een grafkist van de markies van Dai uit de $2^{\mathfrak{c}}$ eeuw v.Chr., gevonden in de plaats Changsha in de Centraal-Chinese provincie Hunan, twee herten afgebeeld op de kopse kant van de kist. ${ }^{5}$ Nog eerder vervulden herten en geweien toka 


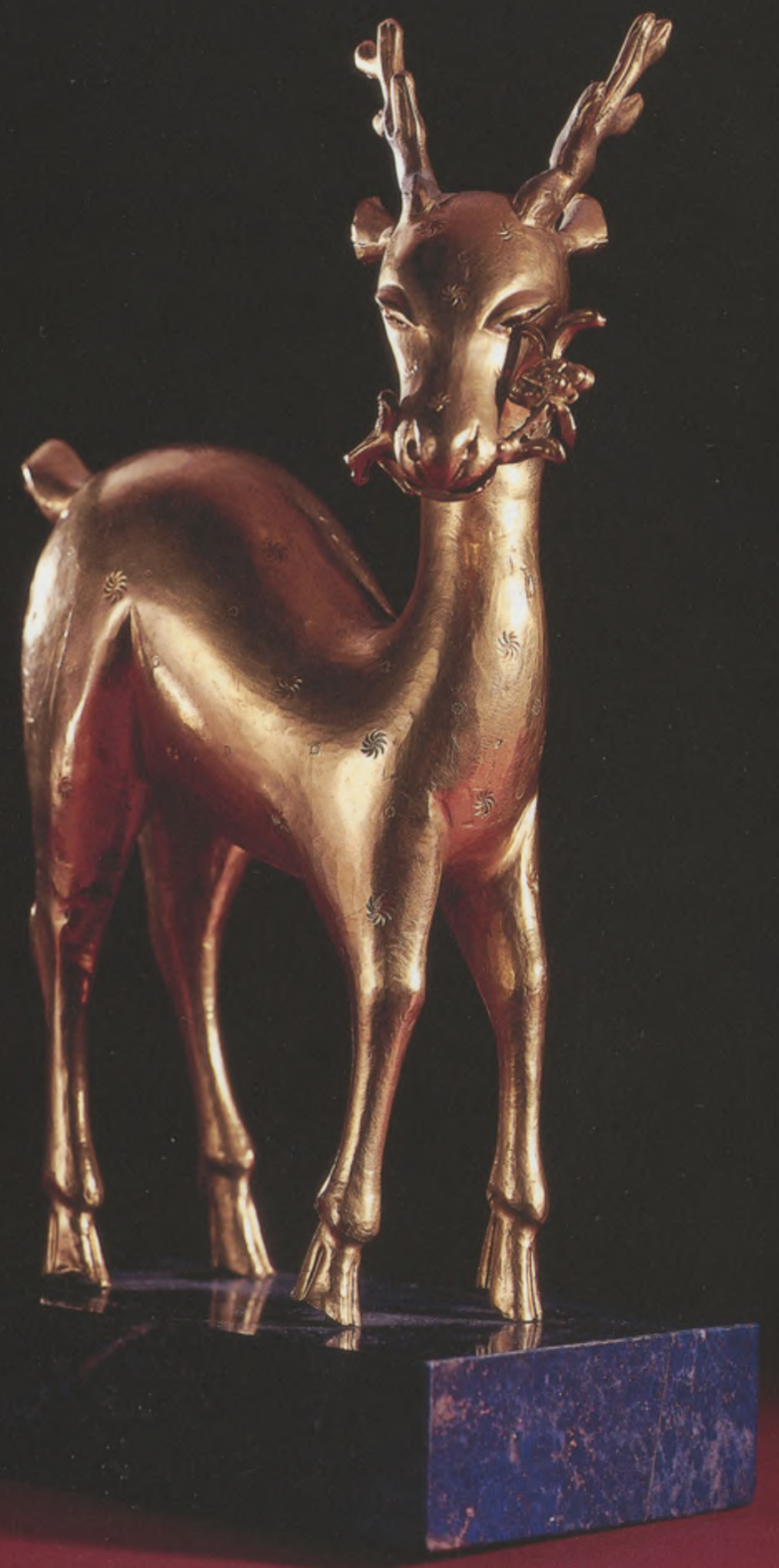


deze streek eveneens een belangrijke rol, namelijk in het Chu-koninkrijk, dat in de $5^{\mathrm{e}}$ en $4^{\mathrm{e}}$-eeuw een deel bestreek van de provincies Hubei en Hunan. In een graf uit de $5^{\mathrm{e}}$ eeuw v.Chr. waren met lak versierde herten van hout bij het

Afbeelding 1 Hert, goud en lapis lazuli h. $18,6 \mathrm{~cm}$. China, $18^{e}$ eeuw Rijksmuseum, inv.nr. AK-RBK-17525 hoofdeinde van de kist geplaatst (afb. 2). Deze spectaculaire figuren van meer dan een halve meter hoog hadden waarschijnlijk tot functie het graf en de overledene te beschermen. ${ }^{6}$ Hertenfiguren uit een ander graf in de regio zijn uitgerust met een trommel op een standaard op de rug, terwijl ook andere wachterfiguren met geweien, combinaties van vogel- of andere mythische dieren, als trommelstandaard hebben gediend. ${ }^{7}$ De complexe betekenis van deze mythische beesten is niet helemaal meer boven water te halen, al is wel duidelijk dat geweien voor de Chu magische (beschermende) krachten bezaten. ${ }^{8}$

Het hert als metgezel van de God van het Lange Leven (Shoulao) duikt voor het eerst op in de vroege Ming-tijd (1368-1644), op een laat $15^{\mathrm{e}}$-eeuwse schildering (afb. 3). De witte kleur van zijn vacht duidt mogelijk op de hoge leeftijd die hij geacht werd te kunnen bereiken. Rond deze tijd lijkt het hert de vaste begeleider te zijn geworden van Shoulao en tot op de dag van vandaag is het een vaste combinatie gebleven. ${ }^{9}$ In het algemeen lijkt het pantheon van goden in de vroege Ming-tijd vastgelegd te zijn. Shoulao werd toen onderdeel van een vast trio van geluksgoden: samen met die voor Geluk $(f u)$ en Rijkdom (lu) werd het bekende drieluik van gelukwensen fulushou gevormd. ${ }^{10}$

\section{Herten van goud}

Het hert werd een regelmatige verschijning in de latere kunstnijverheid. Op porselein is het een geliefd motief, waar het is te vinden op stukken in Kraakstijl en het latere porselein uit de $17^{\mathrm{e}}$ en $18^{\mathrm{e}}$ eeuw. ${ }^{11}$ Onlangs werd nog een bijdrage in dit tijdschrift gewijd aan het voorkomen van het hert en in bijzonder het Pater Davidshert op porselein. ${ }^{12}$ Dit mythische hert van goud lijkt evenmin aan alle criteria van het Pater Davidshert te voldoen, al heeft het wel een aantal van zijn kenmerken. Het gewei ontbeert een oogtak, de snuit is langgerekt, de hoeven zijn gespleten en de vrolijk wapperende staart is ook vrij lang. Tegen de toewijzing spreken de vlekken in de vorm van spiraalvormige lijntjes (het Pater Davidshert heeft geen tekening) en de afwezigheid van lang nekhaar.

Hertenfiguren van goud zijn een zeldzame verschijning. Figuren van herten met de obligate lingzhi in de mond werden veel in jade gemaakt en er zijn bekers gesneden uit neushoorn en bamboe. Kleine beeldjes als deze waren bij uitstek geschikt als voorwerp op of bij de schrijftafel, als teken van behaald succes of als symbool voor het streven ernaar. De mode voor het gebruik van fijn gedecoreerde gebruiksvoorwerpen op de scholars' desk nam een hoge vlucht in de $17^{\mathrm{e}}$ en de $18^{\mathrm{e}}$ eeuw. Fraai besneden bamboe potten voor de penselen, inktstenen en spatschermen werden met verve verzameld door de ontwikkelde elite. Keizer Qianlong (r. 1736-1795) spande wel de kroon bij het bijeen brengen van een collectie van dergelijke, soms opzichtig versierde voorwerpen. ${ }^{13}$ Dit gouden hert van hoge kwaliteit is zeker niet alledaags voorhanden en Fontein opperde in zijn artikel dan ook 'met het grootste voorbehoud' de mogelijkheid dat een zo kostbaar voorwerp wel eens uit het bezit van Qianlong afkomstig zou kunnen zijn. 

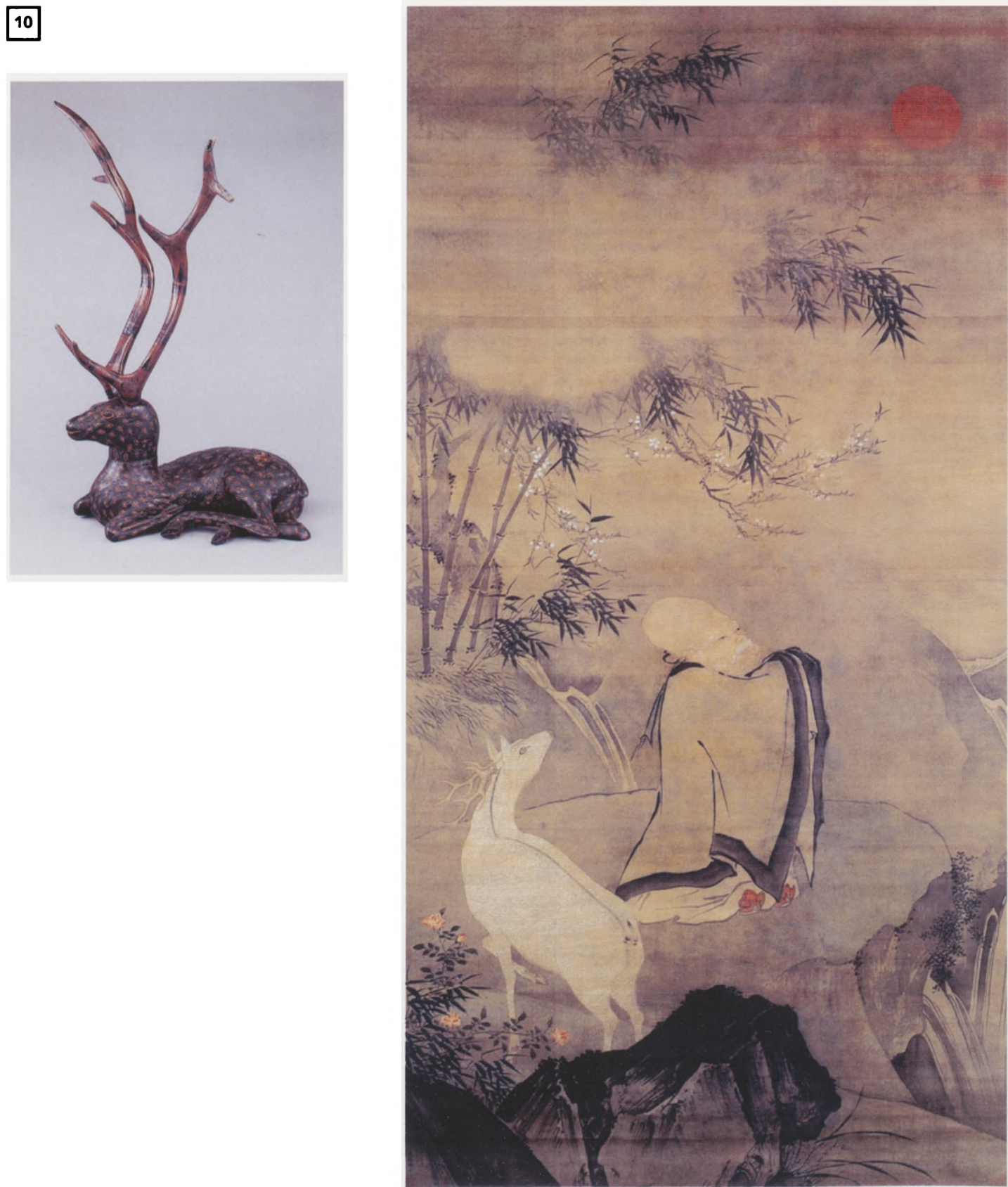

Afbeelding 2

Hert, lak op hout

h. $77 \mathrm{~cm}$.

China, ca. 433 v.Chr.

Uit: The Golden Age of

Chinese Archaeology,

p. 315
Afbeelding 3

Lu Ji (c.1440-1505),

Shoulao vergezeld door een wit hert,

inkt en kleur op zijde

h. $217 \mathrm{~cm}$., b. $114.2 \mathrm{~cm}$.

China, eind $15^{\circ}$ eeuw

Uit: S. Little en

S. Eichman, Taoism and

the Arts of China, p. 268 
De vraag of dit hert eens in een paleisvertrek heeft staan pronken is een mooie bespiegeling waard; in ieder geval is het nu een bijzonder passend symbool voor het verblijf van de afdeling Aziatische Kunst op de Veluwe. Bovendien stond het zo'n vijftig jaar geleden, toen Fontein zijn artikel schreef, ook te pronken in een nieuwe opstelling: in 1952 werden de zalen van het Museum van Aziatische Kunst in het Rijksmuseum geopend.

\section{Noten}

1. Zie bijvoorbeeld C.A.S. Williams, Outlines of Chinese Symbolism and Art Motives, $3^{\mathrm{e}}$ editie, Vermont en Tokyo, 1989, pp. 115-116; W. Eberhard, A Dictionary of Chinese Symbols, Londen en New York, 1986, p.79.

2. J. Fontein, 'Een Chinees gouden hert', in Rijksmuseum Bulletin 1/3,4 (1953), pp. 6264.

3. S. Little en S. Eichman, Taoism and the Arts of China, tentoonstellingscatalogus Art Institute, Chicago en Asian Art Museum, San Francisco, 2000, p. 340.

4. Ibid., p. 363.

5. J. Rawson, Chinese Ornament: The Lotus and the Dragon, New York, 1984, pp. 107 en fig. 68 , p. 90.

6. The Golden Age of Chinese Archaeology: celebrated discoveries from the People's Republic of China, pp. 314-315.

7. Ibid., cat. nr. 100, pp. 296-297

8. Het kan zijn dat de interesse voor de geweien (en de daaraan gehechte geneeskrachtige werking) vanuit Mongolië zijn weg vond naar Chinees-sprekende gebieden. Verder naar het noorden, in een graf in de Chinese provincie Shaanxi, zijn gouden en zilveren hertenfiguren gevonden, die overeenkomsten vertonen met vondsten uit Binnen-Mongolië. Zie C. Michaelson, Gilded Dragons: Buried Treasures from China's Golden Ages, tentoonstellingscatalogus British Museum, 1999, pp. 2627.

9. Shoulao wordt ook wel de 'Oude Man van de Zuidelijke (Hemelse) Pool' genoemd, Shouxing, naar de Ster van het Lange Leven. Shouxing duidde op zowel een deel van de hemel als een specifieke ster: Canopus. Deze ster werd al in de $3^{e}$ eeuw v.Chr. aanbeden door de eerste keizer van de Qin-dynastie (221-207 v.Chr), Qin Shihuangdi. In de $8^{e}$ eeuw werd de traditie opnieuw leven ingeblazen. Little, op.cit., p. 269.

10. De drie geluksgoden, tevens goden van de bijbehorende sterren, zijn in strikte zin eigenlijk niet zozeer taoïstische goden. In de in de $14^{e}$ eeuw gecompileerde Taoïstische Canon (Daozang) komt het trio niet voor en evenmin op een serie van muurschilderingen van meer dan 300 taoïstische goden uit de vroege $14^{\mathrm{e}}$ eeuw. Het is waarschijnlijk dat het oorspronkelijk goden uit het volksgeloof waren, die (mogelijk door het keizerlijk bestuur) aan het begin van de Ming-periode in het taoïstische pantheon zijn opgenomen. Little, op.cit., p. 271.

11. Zie bijvoorbeeld C.J.A. Jörg, Chinese Ceramics in the Collection of the Rijksmuseum, Amsterdam: the Ming and Qing dynasties, Amsterdam, 1997, pp. 56 nr. 36, $98 \mathrm{nr} .88$, 132 en 133 nrs. 138 en 139.

12. K. Witsenburg, 'Het Pater Davidshert op Chinees porselein', in Aziatische Kunst 32/4 (2002), pp. 10-17.

13. Zie bijvoorbeeld C. Ho en B. Bronson, Splendors of China's Forbidden City: The Glorious Reign of Emperor Qianlong, tentoonstellingscatalogus The Field Museum, 2004, of de collectie uit het Nationaal Paleismuseum in Taipei, in de recente catalogus van de tentoonstelling die in Berlijn en Bonn te zien was: Schätze der Himmelssohne: Die kaiserliche Sammlung aus dem Nationalen Palastmuseum, Taipeh, 2003. De catalogus van het Field Museum illustreert een aantal gouden voorwerpen, zoals goud bestek en een gouden wijnkan, die bij officiële diners gebruikt werden (p. 193 en verder). 


$$
1
$$

